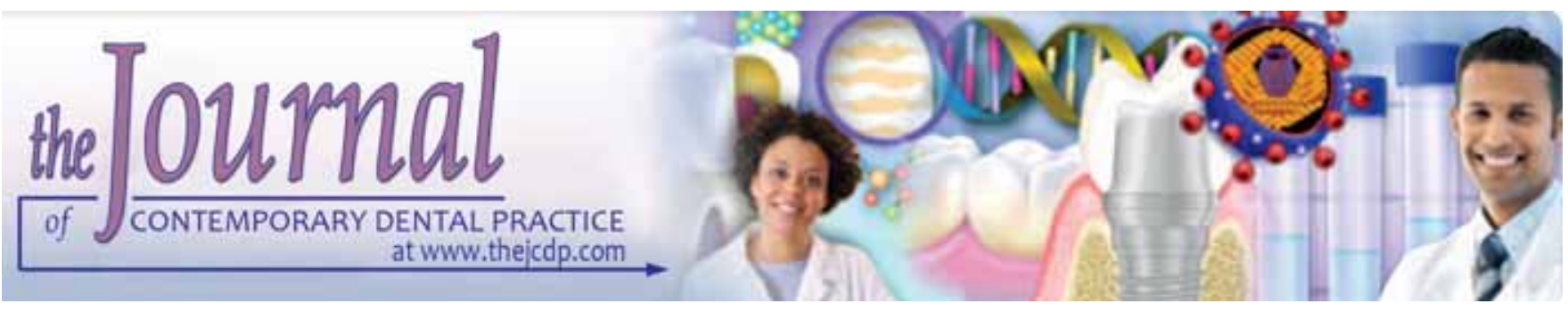

\title{
Revisiting Amalgam: A Comparative Study between Bonded Amalgam Restoration and Amalgam Retained with Undercuts
}

\author{
Indra Gupta, Satyendra Gupta, Anjali Kothari
}

\begin{abstract}
Aim: To compare the retention of amalgam restorations in bonded amalgam restoration and restorations with undercuts.

Background: With improvement in adhesive technology problem associated with conventional preparation for amalgam restorations mainly compromised resistance form of tooth structure have been largely overcome.
\end{abstract}

Materials and methods: Forty caries free extracted molars were used. A basic box preparation was done proximally with buccoproximal and linguoproximal walls diverging at $45^{\circ}$ angle and the axial wall is $1.3 \mathrm{~mm}$ in dentin.

The teeth were randomly divided into 4 groups of 10 each. Group 1 - Teeth with basic box preparation.

Group 2 - Teeth with box preparation for bonded amalgam.

Group 3 - Teeth with box preparation and proximal retention grooves.

Group 4 - Teeth with box preparation and occlusal dovetail.

Group 1, 3 and 4 were restored with silver amalgam and group 2 restored with resin-bonded amalgam. All samples were subjected to simulated occlusal load against marginal ridge using a blunt stainless steel point in an Instron testing machine. The force in kilogram required to dislodge the restorations as well as the type and location of failure were recorded.

Result: The main force required to dislodge the restoration was least in group 1 and 3 and maximum in group 2.

Conclusion: The in vitro study showed that the amalgam bonding technique, using an adhesive resin liner in proximal box form preparation, was more effective than either box form with proximal grooves or dovetails or proximal box only in providing resistance to displacement.

Clinical significance: Amalgam bonding eliminates the unnecessary removal of sound tooth structure during cavity preparations.

Keywords: Undercuts, Bonded restorations, Amalgam.

How to cite this article: Gupta I, Gupta S, Kothari A. Revisiting Amalgam: A Comparative Study between Bonded Amalgam Restoration and Amalgam Retained with Undercuts. J Contemp Dent Pract 2011;12(3):164-170.

Source of support: Nil

Conflict of interest: None declared

\section{INTRODUCTION}

In this world of composites, amalgam, though controversial, has served effectively as a dental restorative material since its introduction in the 1830s. Amalgam has many advantages including ease of manipulation, long clinical service, good abrasion resistance, dimensional stability and low cost. It is one of the least technique sensitive direct restorative material.Set of disadvantages include in particular microleakage and a lack of adhesion to the tooth structure which limits its use in certain clinical situations.

Amalgam restorations have traditionally been retained in cavity preparations by retention forms including grooves, occlusal dovetails and undercuts. In very extensive cavities with gross tooth loss, pins were used, however the placement of a pin can endanger a pulp, and set up stresses ${ }^{1}$ in the already weakened tooth structure. In small interproximal lesions, caries removal does not always result in cavities having sufficient retention and resistance form to hold amalgam under occlusal loads. Thus, sound, non-carious tooth structure must be removed in order to create a retentive cavity preparation. ${ }^{2}$ Removal of sound tooth structure by cavity preparation has been shown to weaken tooth and to increase its susceptibility to fracture. ${ }^{3-7}$ Composite resins that have been bonded to enamel increase the fracture resistance of the teeth. The major shortcomings of the composite resins have been rapid wear and the sequelae polymerisation shrinkage in functional areas of posterior teeth.Gold and porcelain inlays bonded to teeth have also shown to increase fracture resistance. A restoration that has durability and that increases the fracture resistance of tooth and has good bond strength to tooth is desirable. ${ }^{5}$

Recently, adhesive resins have been used as cavity liners in an attempt to reduce leakage and provide retention of amalgam restorations. The purpose of this study was to 
evaluate the use of resins based on Bis GMA (Panavia-Ex) under amalgam restorations in cavity preparation without undercuts and to compare the retention of bonded amalgam restorations to undercut-retained restorations under simulated occlusal loads.

\section{MATERIALS AND METHODS}

An in vitro study was carried out to compare retention of amalgam restoration in cavities with undercuts and those without undercuts, but where the amalgam restorations were bonded to tooth structure with the help of an adhesive liner.

The materials used were:

(A) Panavia Ex (Kuraray Company, Osaka, Japan): It is a dental adhesive kit containting 10-Methacryloyloxydecyl Dihydrogen Phosphate-MDP.

Powder: Consists of quartz filler, radiopaque filler and initiators.

Liquid: Consists of aromatic methacrylates, aliphatic methacrylates, phosphate monomer, activators and stabilizers.

\section{Etching agent:}

1. Gel

2. Liquid

Both contain $40 \%$ phosphoric acid.

Oxyguard: (Oxygen inhibiting gel) it contains polythene glycol gel. As panavia is an anaerobic setting cement which must be free from oxygen in order to polymerize, it is covered by oxyguard wherever exposed at the margins.

(B) Vitrebond (Light cured glass ionomer cement): (3M Dental products division, St Paul, MN) it consists of a powder and liquid components. Powder is a light sensitive fluoroaluminosilicate glass. Liquid component consists of water, light curable polymer, a photosensitizer and 2-HEMA (hydroxyethyl methacrylate) which is coreactive with the polymer.

(C) Silver amalgam (De Trey’s Solila alloy)

\section{Methods}

The study used 40 extracted molars of approximately the same size, that were free of caries and other defects. All teeth were stored in tap water at room temperature after extraction and between restorative and testing procedures.

Each tooth recieved a basic box preparation proximally with the buccoproximal and linguoproximal walls diverging at a $45^{\circ}$ angle and the axial wall is $1.3 \mathrm{~mm}$ in dentin (Fig. 1).

All preparations were cut with a flat fissure carbide bur in a high-speed handpiece with water spray. All preparations were cut to the same size and shape as much as possible, by the same operator, same burs to gauge the depth and width. The basic preparation was a proximal box form with rounded

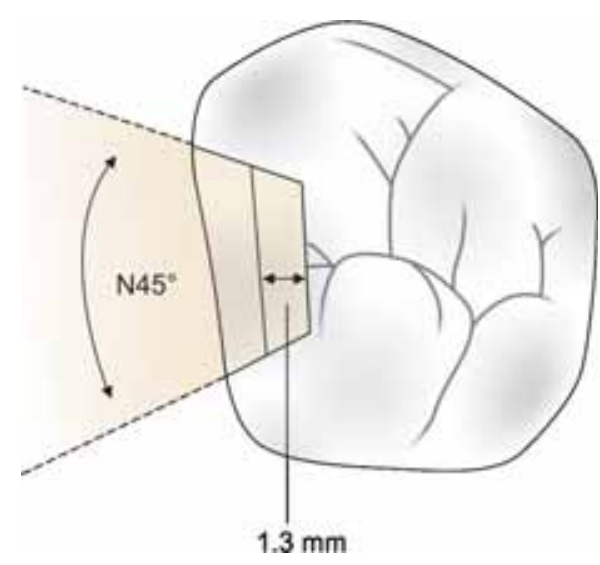

Fig. 1: Basic box form preparation

line angles, as produced by the bur, without undercuts or retentive features. The central fossa of each tooth was slightly deepened. After all preparations had been cut, the teeth were randomly divided into four groups of 10 teeth each.

Group I: Teeth with basic proximal box preparation and silver amalgam restoration.

Group II: Teeth with box preparation and bonded (with Panavia Ex) silver amalgam restorations.

Group III: Teeth with box preparation and proximal retention grooves added for silver amalgam restorations (Fig. 2).

Group IV: Teeth with box preparation and occlusal dovetail added for silver amalgam restorations (Fig. 3).

The teeth in groups I, III and IV were restored with silver amalgam (Solila alloy, De Trey). The preparation was rinsed with water spray and dried with an air syringe for 15 seconds. A matrix band with an ivory retainer no. 1 was placed. The amalgam was triturated manually according to the manufacturer's instruction and condensed into the preparation using vertical and lateral pressure. The amalgam was carved to anatomic contour.

Teeth in group II were restored with resin bonded amalgam restorations. A glass-ionomer liner (Vitrebond$3 \mathrm{M}$ dental products), mixed according to the manufacturer's directions, was applied to the dentin to a thickness of $0.5 \mathrm{~mm}$ and it was light cured for 40 seconds. After

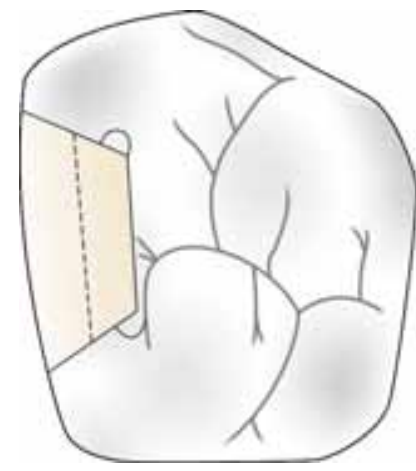

Fig. 2: Addition of proximal grooves 


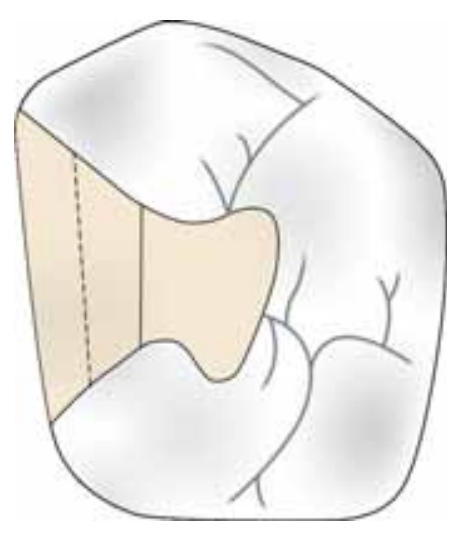

Fig. 3: Addition of dovetail

5 minutes, the enamel was etched with Panavia etching gel for 20 seconds, rinsed with water for 30 seconds and dried with an air syringe for 15 seconds. A thin layer of freshly mixed adhesive resin (Panavia, Kuraray Co) was painted on to the cavity walls, including the liner, with a fine brush. In the mean time, the amalgam was mixed so that the cavity can be restored with silver amalgam when the panavia is still wet. A matrix band with an ivory retainer no. 1 was placed on the tooth and the amalgam was condensed and carved in the same manner as for the other groups (The matrix band and all metallic instruments are coated with a varnish so that Panavia does not bind to them). After carving, the amalgam restorations in group II were covered with a polyvinyl alcohol gel (Oxyguard, Kuraray Co) for 6 minutes to exclude oxygen and allow complete polymerization of the resin at the margins. After restoration, all four groups of teeth were rinsed with water and stored in water for 14 days before testing.
To test the retention of the restorations, the restored teeth were mounted in a base of self-cured acrylic resin within a metal ring of $2 \mathrm{~cm}$ diameter, exposing only the crown portion of the teeth. The teeth were mounted with their axis at a $45^{\circ}$ angle with the base of ring (Fig. 4). The mounted teeth were placed in Instron testing machine (Instron Corp), and the restoration was loaded with a simulated occlusal force against the marginal ridge, using a blunt stainless steel testing point. The load was applied at a crosshead speed of $5 \mathrm{~mm} /$ minute until the restoration was dislodged from the tooth. The force (in kilogram) required to dislodge the restoration, as well as the type and location of failure, was recorded.

The finding were as tabulated (Tables 1 and 2).

Group I: The range of force for group I was 12 to $31 \mathrm{~kg}$ and the mean force was $23.6 \mathrm{~kg}$. It is the least force required compared to all the other groups.

Group II: As shown in Table 2, the range for group II was 36.5 to $76 \mathrm{~kg}$, the mean force being $54.2 \mathrm{~kg}$. This group needed the maximum force to dislodge the restorations, which were sometimes as high as $76 \mathrm{~kg}$.

Group III: As shown in Table 2, the range for group III was 17 to $46 \mathrm{~kg}$ and the mean was $31.8 \mathrm{~kg}$.

Group IV: The range of force required to dislodge the restorations was 30 to $60 \mathrm{~kg}$ and the mean force was $42.25 \mathrm{~kg}$. This group needed more force than group I and II to dislodge the restorations.

In group II, one restoration dislodged at a force as low as $16.5 \mathrm{~kg}$, which was quite low as compared to other

\begin{tabular}{rcccc}
\multicolumn{5}{c}{ Table 1: Maximum force required to dislodge amalgam restorations (in kg) } \\
\hline S. No. & $\begin{array}{c}\text { Group I } \\
\text { Proximal box form }\end{array}$ & $\begin{array}{c}\text { Group II } \\
\text { Box form and } \\
\text { adhesive liner }\end{array}$ & $\begin{array}{c}\text { Group III } \\
\text { Box form and } \\
\text { proximal grooves }\end{array}$ & $\begin{array}{c}\text { Group IV } \\
\text { Box form and } \\
\text { dovetail }\end{array}$ \\
\hline 1 & 31 & 49.5 & 46 & 34 \\
2 & 25 & 48.5 & 27.5 & 49.5 \\
3 & 29 & 60 & 45 & 30 \\
4 & 22 & 36.5 & 36 & 34 \\
5 & 30 & 76 & 30.5 & 60 \\
6 & 26 & 72 & 28 & 38.5 \\
7 & 16 & 47.5 & 35 & 36 \\
9 & 24 & 51 & 21 & 42 \\
\hline
\end{tabular}

\begin{tabular}{lcccc}
\multicolumn{2}{c}{ Table 2: Statistical summary of forces required to dislodge amalgam restorations in various groups } \\
$\begin{array}{l}\text { Group I } \\
\text { Proximal box form }\end{array}$ & $\begin{array}{c}\text { Group II } \\
\text { Box form } \\
\text { and adhesive liner }\end{array}$ & $\begin{array}{c}\text { Group III } \\
\text { Box form and } \\
\text { proximal grooves }\end{array}$ & $\begin{array}{c}\text { Group IV } \\
\text { Box form and dovetail }\end{array}$ \\
\hline Number of teeth & 10 & 10 & 10 & 10 \\
Range & $12-31$ & $36.5-76$ & $17-46$ & $30-60$ \\
Mean & 23.60 & 54.20 & 31.80 & 42.25 \\
Standard deviation & 06.09 & 11.96 & 09.27 & 10.62 \\
Coefficient of variation & 25.80 & 22.07 & 29.16 & 25.13 \\
\hline
\end{tabular}


Revisiting Amalgam: A Comparative Study between Bonded Amalgam Restoration and Amalgam Retained with Undercuts

\begin{tabular}{lcccccc}
\hline \multicolumn{1}{c}{ Table 3: Type of bond failure } \\
No. of failures \\
\hline Group no. & $\begin{array}{c}\text { Between } \\
\text { tooth and } \\
\text { amalgam }\end{array}$ & $\begin{array}{c}\text { Within } \\
\text { amalgam in } \\
\text { box form }\end{array}$ & $\begin{array}{c}\text { Within amalgam } \\
\text { at axipulpal line } \\
\text { angle }\end{array}$ & $\begin{array}{c}\text { Between } \\
\text { Gl and } \\
\text { amalgam }\end{array}$ & $\begin{array}{c}\text { Between } \\
\text { Gl and } \\
\text { dentin }\end{array}$ & $\begin{array}{c}\text { Within } \\
\text { enamel }\end{array}$ \\
\hline Basic box form only (10) group I & 8 & 2 & - & - & - & - \\
Box form and adhesive liner (10) group II & 2 & 9 & - & - & - & 0 \\
Box form and proximal grooves (10) group III & 9 & 8 & - & - & - \\
Box form and dovetail (10) group IV & 6 & 5 & 8 & - & - & - \\
\hline
\end{tabular}

\begin{tabular}{ll} 
& \multicolumn{1}{c}{ Table 4: Student's t-test } \\
\hline Groups & \multicolumn{1}{c}{$t$-values } \\
\hline I vs II & $7.216^{* \star *}$ \\
I vs III & $2.34^{*}$ \\
I vs IV & $4.90^{* *}$ \\
II vs III & $4.68^{* \star *}$ \\
II vs IV & $5.05^{\star * *}$ \\
III vs IV & $2.34^{*}$ \\
\hline
\end{tabular}

* $p<0.05 ;{ }^{* *} p<0.01 ; * * * p<0.001$.

The student's t-test showed that all means were significantly different.

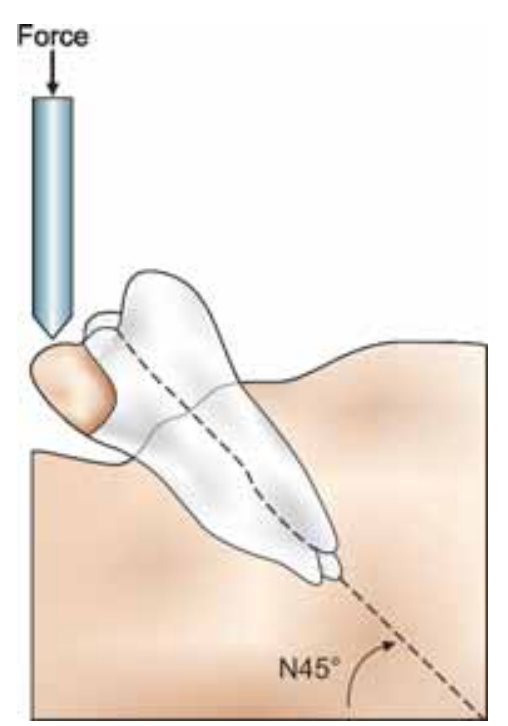

Fig. 4: Mounted tooth under simulated occlusal load

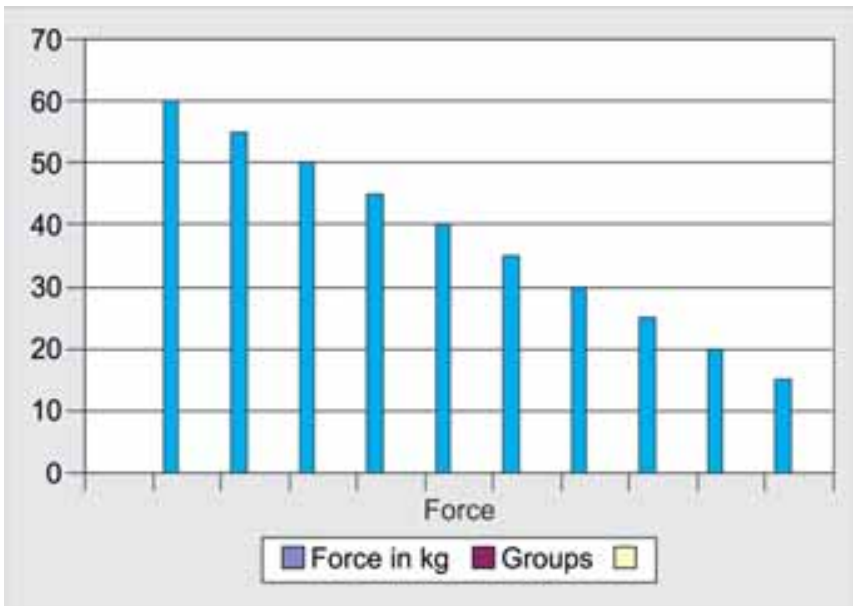

Fig. 5: Mean values (in $\mathrm{kg}$ ) for the forces required to fracture various groups restoration in the group. This can probably or faulty technique while restoring. So that finding was excluded in statistical analysis.

The types of failures exceeded number of restorations because many restoration showed multiple modes of failure. In group I, generally the amalgam came out of the preparation in one piece only. In group II, a combination of failures was usually observed in a single tooth. In two cases, pieces of enamel remained attached to the dislodged restoration. In group II, failures included that between the adhesive resin and amalgam, between the resin and enamel and within the resin. Because of the thinness of the resin and irregularity of the surfaces, it would have been difficult to differentiate. In group III, pieces of amalgam remained in retention grooves in all cases, sometimes as a continuous piece across the axial wall. In group IV, amalgams fractured at the axiopulpal line angle and the entire box form portion became dislodged with two exceptions, in which some amalgam remained in the box form. There were significantly less failures between the tooth and amalgam in group II than in all other groups (Table 3).

According to Table 4 ' $t$ '-test showed that group II was better than all the other groups. This is also shown in Figure 5.

\section{DISCUSSION}

The purpose of a restorative material is not only to restore the decayed tooth but also to strengthen the tooth and provide adequate bonding and an effective seal between the restoration and the tooth.

Under the conditions of this study, the results show that the adhesive technique resulted in the highest resistance to dislodgement by the restoration. In many cases, the amalgam to enamel bond mediated by the adhesive resin liner exceeded the cohesive strength of enamel, resulting in fractures within enamel. ${ }^{8}$ Because of lack of adhesion between tooth and amalgam, all restoration in group I, III and IV failed between the amalgam and the tooth, but this was often not the case in group II. The retention of group I restoration was low, as expected, but when the bonding technique was used in the same preparations in group II, the retention increased much more. It appears that it is possible to prepare cavities for amalgam restorations without 
undercuts, such as dovetails or proximal grooves, if a bonding technique is used. This technique can conserve tooth structure by requiring removal of only the carious part of the tooth after access to it is gained.

Class II cavity preparations for amalgam restorations have evolved into more conservative forms since the times of GV Black. Although some might suggest that modern cavity is too conservative, it appears that the current style of preparation and current amalgam leads to a good result. We do not know that the so-called immune areas really do exist for there is no such thing as a self-cleansing surface. ${ }^{9}$ The aim of the dental profession should be to preserve healthy teeth for a lifetime. As life expectancy is extended, the teeth and surrounding tissue should last longer. We are no longer practicing a radical "Extension for Prevention" but have changed the slogan to "Constriction with Conviction".

Present class II restorations fail some years ${ }^{3}$ after placement. The reasons for this lie initially in the fact that in current restoration design, the amalgam takes no part of the load directly imposed on the cusps. Such loads are always present when eating and may be quite high when something hard is bitten or quite small during normal function. In either case, there is a concentration or tensile stress in the bottom corners of the prepared cavity and cracking in these regions have been observed. The brittle nature of both enamel and dentin has been established. Every time a tensile stress occurs in the brittle material where there is a crack, there is a possibility that the crack will be extended. Propagation generally occurs in the direction of greatest stress gradient. The failure mechanism is defined as: "If, after the cavity preparation, cracks exist in the tooth tissue in the region of the bottom corner of the cavity, then the tooth will probably suffer eventual cuspal failure”. Obviously, not all the teeth are so cracked, in those, that are, the crack will act as an initiation point for progressive failure. With each imposed load on the cusps, the crack may propagate by small amount in roughly the observer direction of the failure planes. Over a period of years, the structural integrity of this part of the tooth is gradually weakened. Finally, when the cusp has become very weak at which time some pain may be felt, there is a catastrophic failure, frequently caused by simple overload. Obviously, such failures will continue unless some change is made to clinical practice. Most variation of the convention cavity preparation appears to be susceptible to failure. The locked type of the cuspal overlay should be successful in terms of restoration life but runs contour to connect dental persuasion in respect of removal of material and is esthetically unacceptable. For this reason, it is worth pursuing the possibility of bonded amalgam restoration, because it meets the criteria of dental practice and has the potential to extend the life of restoration indefinitely.
In 1985, Childers ${ }^{10}$ reviewed the literature concerning retention grooves and concluded that the need for placing grooves was controversial. He began his article by stating that "One of the more difficult task for dental students, to accomplish, is the accurate and adequate instrumentation of proximal retentive grooves". He continued by saying that many, otherwise well-instrumented cavity preparations were mutilated by poor instrumentation of the retentive grooves by dental students and it is probable that many teeth treated in private practice also suffer rotary abuse. Moore ${ }^{11}$ (1991), surveyed dental schools in US to determine the extent to which retention grooves are taught for class-II amalgam preparations. Fifty-nine out of the 64 schools surveyed responded and 36 or $61 \%$ of those responding reported that retention grooves are taught.

In modern cavity preparation, isthmus width and the proximal and gingival extensions are smaller. ${ }^{12}$ Partly because of concern about weakening the tooth and predisposing it to fracture ${ }^{4,6}$ and partly because for the superior marginal integrity of above conservative restoration, ${ }^{13,14}$ authors have recommended alternative preparation design, such as eliminating the isthmus and the dovetail portion entirely for teeth without caries in occlusal pits and fissures. The facial slot preparation uses an entirely different access for caries removal ${ }^{15}$ while the box form only preparation retain just that point of the traditional preparation. ${ }^{16}$ Studies of amalgam restoration have concentrated mainly on the amount of undercut necessary. Terkla et al, ${ }^{17,18}$ studied amalgam restoration in conventional preparation with or without proximal grooves and concluded that such grooves are unnecessary. Crockett et al, ${ }^{16}$ using metal dies in vitro, concluded that proximal grooves increase the resistance to displacement when a horizontal force is applied. Box form preparation with and without isthmus and dovetail was studied and author concluded that when grooves are placed, the tooth structure of the occlusal portion of the tooth can be saved. Studervant et $\mathrm{al}^{19}$ completed a clinical study of three cavity designs and concluded that box form only preparation can be successful, provided that full length retention grooves are placed, rather than the short conventional type.

With silver amalgam restorations, it has been impossible to conserve undermined enamel. A basic rule of cavity preparation is the removal of unsupported enamel to prevent fracture. Frequently undermined enamel is limited to the cavosurface marginal area and the removal involves only minor overextension of the preparation. ${ }^{20}$ At other times, however, dentinal destruction and the enamel undermining are extensive or exist in an area where the only alternative is total removal of a cusp of removal of a large area of labial enamel. If true dental adhesive was developed: One that would adequately bond to tooth structure, it would not be necessary to remove undermined enamel. In bonding to the 
undermined enamel, the adhesive restorative material would lent the weakened area, the support necessary to withstand masticatory forces. Landly NA et al, Bakk JC et al, Mackenzie DF have shown that the weakening effect of the cavity preparation can be alleviated with the use of such materials. The fracture resistance of the tooth restored with adhesive material is increased by 80 to $362 \%$.

Teeth restored with amalgam bonded to etched enamel with a resin cement had a significantly greater fracture resistance than teeth restored with conventional amalgam. ${ }^{15}$ The adhesive resin used in this study develops micromechanical restoration with etched enamel in the same way as other restorative resins do. It may also develop some chemical bonds via phosphate esters that interact with calcium ions in the tooth. When amalgam is packed into the cavity over the wet resin, a mechanical interlocking of resins and amalgam occurs. This interlocking is probably a much more significant factor in retention of amalgam than are the chemical bonds that occur between the resin and the components of the amalgam as Lacy et al have suggested.

Enamel fissures can be sealed as well as the tooth amalgam interface, ${ }^{21}$ this adhesive technique could be used in place of extension for prevention, thus saving unnecessary removal of tooth structure. Such a technique has been described for composite resin restoration, thus so-called "Preventive resin restoration”, combining composite resin and sealant (Simmonsen, 1980). Composite resins have not yet attained universal acceptance as a suitable direct filling material for posterior teeth (Bells and Gilbert 1987). However, avoiding unnecessary removal of healthy tooth should certainly be the goal of a conscientious operator. When compared with bonded composite restoration, the bonded amalgam restoration exhibited less leakage above the cementoenamal junction, presumably because shrinkage on setting is much less than the polymerization shrinkage of composite resin (Staninec, Wada and Watanabe, 1988). ${ }^{22}$

Even adhesive restorative materials, not to mention nonadhesive traditional ones, always have a microscopic space between the restoration and the cavity walls. This microscopic space has been demonstrated by the use of radioisotopes, tracers, dyes, the microscope and other techniques. Since, under in vivo conditions, oral fluids, acids and microorganisms may penetrate freely into this microscopic space, the cavity walls would be in danger of secondary caries at all times. For the prevention against secondary caries, it would be very important not only to minimize microleakage itself but also to provide the cavity walls with an anticariogenic property. The mediation of resin cement and glass ionomer cement at the amalgam tooth interface would reduce the microleakage and the fluoride treatment of tooth tissue may increase the resistance to carious attack. Glass ionomer used under Panavia Ex in this study is a very useful material. First of all, it protects the dentin from the etchant and the irritation effect of Panavia. Second, as Panavia Ex is an anaerobic cement, in presence of dentinal fluid (containing oxygen), it binds less and sets slowly. So glass ionomer helps in increased binding. Then, glass ionomer also releases fluoride thereby providing the walls with an anticariogenic property. Vitrebond, light-cured glass ionomer cement, also shows increased bonding to resins. ${ }^{23}$ In light-cured glass ionomer cement, first, unpolymerized HEMA on the surface of vitrebond after curing may penetrate and facilitate wetting of the resin bonding agents and composite resin during bonding. Second, the availability of residual unreacted methacrylate groups on the polyacid chain within the polymerized, light-cured glass ionomer cement may form strong covalent bonds to the resin bonding agent. Also etching of vitrebond with $37 \%$ phosphoric acid prior to bonding is not necessary.

The present study compared bonded restorations those retained by conventional grooves alone or dovetails alone. Although the adhesive technique provided much greater retention than grooves or dovetails, there are some limitations to this study. Because the duration of the study was short, any possible deterioration of the bond over time cannot be observed. The initial bond obtained in vivo should be similar to that obtained in the study; however, because presumably most of is derived from the bond to enamel. comparison of enamel bonds in vitro and in vivo show little variation. However, the smaller component of the bond strength, derived from the bond to the glass ionomer liner, which in turn is bonded to dentin, might be less in vivo. Also, the effect of corrosion on the bond strength need to be investigated.

It might be agreed that it is not desirable to have amalgam bonded to the tooth so strongly that enamel will fracture upon dislodgement of the restoration. However, such dislodgement is unlikely to occur. As Terkla et al, ${ }^{17,18}$ have shown amalgam restoration in preparation without proximal grooves, which would correspond to group IV in the present study, performed well clinically, without fracture or dislodgement. Group II restoration in the present study, using the bonding technique, had much more resistance to dislodgement than group IV restoration.

Additionally, there are other advantages to the bonding techniques, some of which have been reported from experiments in vitro. Microleakage as mentioned by dye penetration is decreased ${ }^{24}$ and recurrent caries as measured by wall lesion formation is inhibited. ${ }^{21}$ Another reported advantage is increased resistance of restored teeth with bonding technique to fracture.

In $1992,{ }^{5}$ study carried by Eakle WS, Staninec M and Lacy AM showed that there was significant increase in fracture resistance of bonded amalgam restorations as compared with conventional amalgam restorations. 
Further improvements are needed in the bonded amalgam restorations and additional laboratory studies and studies in vivo are needed before these materials can be recommended for routing use under amalgam restoration eliminating undercuts in clinical practice.

\section{CONCLUSION}

The following conclusions were drawn from the study:

1. The amalgam bonding technique, using an adhesive resin liner in proximal box form preparations, was more effective than either box form only in providing resistance to displacement under simulated occlusal load.

2. Amalgam bonding technique eliminates the need for unnecessary removal of sound tooth structure during cavity preparation.

3. The amalgam bonding technique shows promise and need to be tested in a controlled clinical trail.

\section{CLINICAL SIGNIFICANCE}

The retention is almost equal, though amalgam bonding technique does not show a significant increase in retention but does help in eliminating the compromise in resistance form. However, the cost of bonding has to be considered.

\section{ACKNOWLEDGMENTS}

Dr Girish Parmar, Dr Michael Staninec, Mr Yoshinori Nagase are acknowledged by the authors for their support.

\section{REFERENCES}

1. Causton Temple-Smithson PE, Marshall BE KF. The adhesive amalgam: Fact of fiction. Brit Dent J 1922;172: 282,316-19.

2. Staninec M. Retention of amalgam restorations: Undercuts versus bonding, Quintessence Int 1989;20(5):347-51.

3. Bell JG, Smith MC, Pont JJ De. Cuspal failure of MOD restored teeth. Aust Dent J 1982;27(5):283-87.

4. Blaser PK, Lund MR, Cochran MA, Potter RH. Effects of design of class II. Preparations on resistance of teeth to fracture. Oper Dent 1983;8:6-10.

5. Eakle WS, Staninec M, Lacy AM. Effect of bonded amalgam on the fracture resistance of teeth. J Prosthet Dent 1992;53:257-20.

6. Larson TD, Douglas WH, Geistfeld RE. Effect of prepared cavity on the strength of the teeth. Oper Dent 1981;6:2-5.

7. Mondelli J, Ishikiriama A, Navarro MFDL, Galan J Caradazzi JL. Fracture strength of human teeth with cavity preparations, J Prosthet Dent 1974;43(4):419-22.

8. Charlton DG, Moore BK, Swartz ML. In vitro evaluation of the use of resin liners to reduce microleakage and improve retention of amalgam restoration. Oper Dent 1992;17, 112-19.

9. Ottolengui R. Extension for prevention: Items of interest 1901;23:322-333, cited from Halla Sigurjons. "Extension for prevention”. Historical development and current status of GV Black’s concept. Oper Dent 1983;8:57-63.

10. Childers JM. Approximal retentive grooves in cavities prepared for amalgam: Historical and current assessment. Oper Dent 1985;10:100-03. Cited from Summit JB, Howell ML, Burgess JO, Dutton FB, Osborne JW. Effect of grooves on resistance from the conservative class II amalgams. Oper Dent 1992;17F: 50-56.
11. Morre DL. Retention grooves for the class II amalgam restoration. Necessity or Hazard Oper Dent 1992;17:29-33.

12. Rodda JC. Modern class II amalgam cavity preparations. NZ Dent J 1972;68:132-38. Cited from Staninec M. Retention of amalgam restorations: Undercuts vs bonding. Quintessence Int 1989;20(5):347-71.

13. Berry TG, Laswell HR, Osborne JW, et al. Width of isthmus and marginal failure of restorations of amalgam. Oper Dent 1981;6:55-58.

14. Osborne JW, Gale EN. Failure of the margin of amalgams as affected by cavity width, tooth position, and alloy selection. J dent Res 1981;60:681-85.

15. Roggenkamp CL, Cochran MA, Lund MR. The facial slot preparation: A nonocclusal option for class II carious lesions. Oper Dent 1982;7:102-06. Cited from Staninec M. Retention of amalgam restoration: Undercuts versus bonding, Quintessence Int 1989;20(5):347-51.

16. Crockett WD, Shephard FE, Moon PC, Creal AF. The influence of proximal retention grooves on the retention and existence of class II preparations for amalgams. J Am Dent Assoc 1975;91:1053-60.

17. Terkla LG, Mahler DB. Clinical evaluation of interproximal retention grooves in class II amalgam cavity design. J Prosthet Dent 1967;17(6):596-602.

18. Terkla LG, Mahler DB, Eysden JV. Analysis of amalgam cavity design. J Prosthet Dent 1973;29(2):204-09.

19. Sturdevant JR, Wilder AD, Roberson TM, et al. Clinical study of conservative designs for class II amalgams. J Dent Res 1988;67:06 (Abstract No. 1549).

20. Jagadish S, Yogesh BJ. Fracture resistance of teeth with cl. II silver amalgam, posterior composite and glass cermet restorations. Oper Dent 1990;15:42-47. Cited from Dr Dipti Desai, unpublished dissertation, Gujarat University 1992.

21. Torri Y, Staninec M, Kawakami M, et al. Inhibition in vitro of caries around amalgam restorations by bonding amalgam to tooth structure. Oper Dent 1989;14(3):142-48.

22. Staninec M, Wada CS, Watanabe LG. Effect of polymerization shrinkage on leakage of class II restoration. J Dent Res 67, abstracts of papers 1988; 196, abstract 667. Cited from Summit JB, Howell ML, Burgess JO, Dutton FB, Osborne JW. Effect of grooves on resistance from the conservative class II amalgams. Oper Dent 1992;17: 50-56.

23. Kerby RE, Knobloch Lisa. The relative shear bond strength of visible light-curing and chemically curing glass ionomer to composite resin. Quintessence Int 1992;20:521-24.

24. Stanince M, Mark Holt. Bonding of amalgam to tooth structure. Tensile adhesion and microleakage tests. J Prosthet Dent 1988;59(4):397-402.

\section{ABOUT THE AUTHORS}

\section{Indra Gupta}

(Corresponding Author)

Professor and Head, Department of Conservative Dentistry and Endodontics, Rishi Raj Dental College, Bhopal, Madhya Pradesh India, e-mail: drindra29068@rediffmail.com

\section{Satyendra Gupta}

Senior Lecturer, Department of Oral and Maxillofacial Surgery Rishi Raj Dental College, Bhopal, Madhya Pradesh, India

\section{Anjali Kothari}

Professor and Head, Department of Conservative Dentistry and Endodontics, AMC-MET Dental College, Ahmedabad, Gujarat, India 